\section{Erythropoietins locked into risk management program}

The US Food and Drug Administration (FDA) and the makers of erythropoietin stimulating agents (ESAs) have agreed on a formal strategy to reduce the risks associated with these drugs. Starting in March, drug makers will operate under a risk evaluation and mitigation strategy (REMS) requiring healthcare providers who prescribe the drugs for cancer patients to register with the drug makers and enroll in a training program on their use. Applying REMS could help ensure these agents, which have been under scrutiny for their potential to cause tumor growth and shorten overall survival, can remain on the market.

Safety concerns for ESAs have been

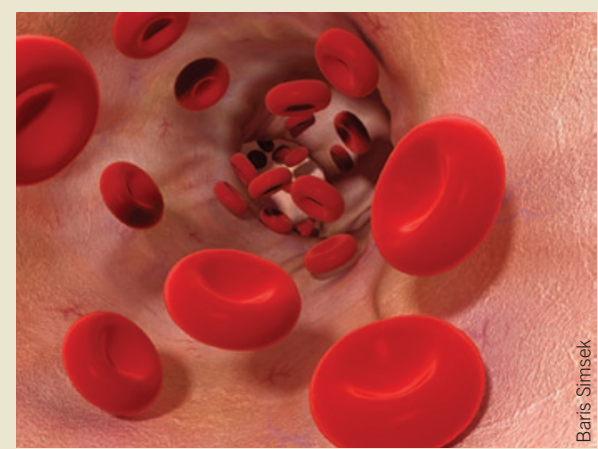

The first erythropoiesis-stimulating agent (ESAs) approved in 1989 revolutionized the treatment of anemia, but over the years safety concerns have been mounting. brewing since the FDA convened a session of the Oncology Drugs Advisory Committee (ODAC) in 2004. In December 2006, the company disclosed clinical trials results showing the potential risks of ESAs when used to treat anemia in cancer patients so they won't need blood transfusions. Another ODAC meeting held in 2007 (Nat. Biotechnol. 25, 607-608, 2007) prompted restrictions in coverage by the Centers for Medicare and Medicaid Services, and later a boxed warning on all versions of epoetin alfa, including Amgen's Aranesp and Epogen, and Procrit, sold by Centocor Ortho Biotech of Bridgewater, New Jersey, a subsidiary of Johnson \& Johnson. Along the way, the drug makers issued "Dear Doctor" warning letters describing the safety concerns and the appropriate use of the drugs.

Now the REMS program mandates distribution of a medication guide to patients and forces drug prescribers and dispensers to enroll in a special program, called APPRISE, and also document that they have discussed the risks of using ESAs before the start of therapy. Although it's taken three years for FDA and the companies involved to devise a risk mitigation plan, a REMS was not an option when the problems with ESAs became apparent. REMS was authorized under the Food and Drug Administration Amendments Act signed in September 2007 (Nat. Biotechnol. 25, 1189-1190, 2007). "You then had almost six months before [the legislation] actually took effect, so it was already March 2008 before you could even begin a conversation about how to apply a REMS to a product," says Michael McCaughan of the Washington, DC, policy consultancy Prevision Policy. "The issues with ESAs came to a head when the FDA's entire drug safety system was under fire on all sides," he adds. "Then you had the situation where basically every study that was done to look at the issue made the problem worse." McCaughan points out that the ESA REMS is "essentially a manufacturer-FDA agreement" and was not developed in as public a process, involving more interested parties, as it could have been. "It's going to be interesting to see what happens over the course of the next year, when a provider actually has to start using this REMS and has to sign up and register in order to continue to use the products," he says.

In an e-mail, an Amgen spokesperson wrote that "multiple parties have been involved in the development of the ESA REMS, and various healthcare providers were consulted to obtain input at various times. However, the main parties involved in the ESA REMS were the FDA, Amgen and Centocor Ortho Biotech." The not-for-profit healthcare provider Kaiser Permanente, of Oakland, California, submitted a citizen's petition last December requesting that FDA obtain input from providers and others, as required by law. The petition claimed that with the exception of the REMS issued for the use of extended release opioids, the agency has not sought such input. Arnold Friede, an attorney in New York and a former FDA associate chief counsel, has a different complaint with the ESA REMS. Through it, he says, the FDA is in effect "controlling the practice of medicine," which is outside the scope of its authority. "I would submit to you that if an oncologist enrolls in the APPRISE program and signs the enrollment form but then prescribes the drug in a manner that differs from the specific terms of the enrollment form, that the doctor runs a serious risk of negligence per se liability should anything go wrong in the treatment," he says.

Mark Ratner Cambridge, Massachusetts

\section{IN brief}

\section{Stem cells to order}

The UK Stem Cell Bank (UKSCB) is relocating to a new building, a move that should boost its growing partnership with the private sector. The Potters Bar-based facility keeps qualitycontrolled, standardized stocks of stem cell lines that it ships to accredited researchers worldwide together with advice on how to use them. Since its inception in 2004, UKSCB, part of the National Institute for Biological Standards and Control, has dealt primarily with academia, but corporate liaisons are on the rise. One recent client is Stem Cells for Safer Medicines (SC4SM), a public-private collaboration between various UK public stakeholders and private investors including GlaxoSmithKline, AstraZeneca and Roche of Basel. As a not-for-profit company, SC4SM is developing improved human cell toxicology assays to test candidate drugs. Frank Bonner, SC4SM's CEO, says the UKSCB is fulfilling "an absolutely vital role" in ensuring the continuity and quality of their research. The facility now carries about 70 human embryonic lines, with induced pluripotent stem cells under evaluation. According to UKSCB director Glyn Stacey, the Bank serves a number of other companies, mostly for laboratory-based in vitro research and toxicology assays, but there are plans to expand the facility's clinical-grade capacity. Currently, neither academic nor corporate users are charged more than delivery, but Stacey says this policy is under review. Jennifer Rohn

\section{ReNeuron first in stroke}

ReNeuron will be treating the first stroke patients with stem cells later this year in the UK after overcoming a string of regulatory holdups abroad. In February, the Surrey-based company received the go-ahead to start a phase 1 trial from the UK's Gene Therapy Advisory Committee (GTAC) for ReN001, a genetically engineered neural stem cell line originally derived from fetal brain tissue. ReNeuron was the first European stem cell company to go public in 2005, but at the time decided to apply for approval with the US Food and Drug Administration (FDA). The FDA, however, repeatedly delayed approval, prompting the company to apply in 2008 to the UK's Medicines and Healthcare Products Regulatory Agency and subsequently GTAC. CSO John Sinden points out that, "We decided temporarily to discontinue discussions with the FDA since we could not afford to run two phase 1 trials in stroke." The recently approved open label dose escalation safety trial will take place at Glasgow's Southern General Hospital in 12 patients and will also evaluate potential efficacy biomarkers using structural and functional MRI. Chris Mason, who heads the Regenerative Medicine Bioprocessing Unit at University College London, says, "Given the degree of scrutiny by the regulators, the phase 1 study should not be a challenge." Mason adds that any unwelcome surprises are more likely to crop up at later stages, due to the heterogeneity of this patient group.

Susan Aldridge 